\title{
Creating space, aligning motivations, and building trust: a practical framework for stakeholder engagement based on experience in 12 ecosystem services case studies
}

$\underline{\text { Heather A. Schoonover }}^{1}, \underline{\text { Adrienne Grêt-Regamev }}^{2}, \underline{\text { Marc J. Metzger }}^{3}, \underline{\text { Ana Ruiz-Frau }}^{4}, \underline{\text { Margarida Santos-Reis }}^{5}, \underline{\text { Samantha S. K. }}^{6}$ Scholte $^{6}$, Ariane Walz $^{7}$ and Kimberly A. Nicholas ${ }^{1}$

\begin{abstract}
Ecosystem services inherently involve people, whose values help define the benefits of nature's services. It is thus important for researchers to involve stakeholders in ecosystem services research. However, a simple and practicable framework to guide such engagement, and in particular to help researchers anticipate and consider key issues and challenges, has not been well explored. Here, we use experience from the 12 case studies in the European Operational Potential of Ecosystem Research Applications (OPERAs) project to propose a stakeholder engagement framework comprising three key elements: creating space, aligning motivations, and building trust. We argue that involving stakeholders in research demands thoughtful reflection from the researchers about what kind of space they want to create, including if and how they want to bring different interests together, how much space they want to allow for critical discussion, and whether there is a role for particular stakeholders to serve as conduits between others. In addition, understanding their own motivations — including values, knowledge, goals, and desired benefits — will help researchers decide when and how to involve stakeholders, identify areas of common ground and potential disagreement, frame the project appropriately, set expectations, and ensure each party is able to see benefits of engaging with each other. Finally, building relationships with stakeholders can be difficult but considering the roles of existing relationships, time, approach, reputation, and belonging can help build mutual trust. Although the three key elements and the paths between them can play out differently depending on the particular research project, we suggest that a research design that considers how to create the space in which researchers and stakeholders will meet, align motivations between researchers and stakeholders, and build mutual trust will help foster productive researcher-stakeholder relationships.
\end{abstract}

Key Words: cocreated knowledge; ecosystem services; participatory research; research design; stakeholder engagement; transdisciplinary research

\section{INTRODUCTION}

To develop solutions to sustainability challenges, researchers from different disciplines need to collaborate both with each other and with other stakeholders (Future Earth 2014). Such collaboration can help ensure the inclusion of the broad range of knowledge necessary to work with complex systems, as well as increase legitimacy, ownership, and accountability for both the problems and potential solutions (Lang et al. 2012). Not only has the number of publications on collaborative approaches between and among academics and nonacademics increased substantially (Zscheischler and Rogga 2015), but such collaborative settings have also been increasingly expected from environmental research (Kueffer and Hirsch Hadorn 2008).

The reasons for engaging stakeholders in research are many, including gaining knowledge from those most deeply connected to a particular resource, issue, or community; achieving buy-in from those most likely to be affected by the research results; and building stronger connections among science, policy, and society (Reed 2008, Luyet et al. 2012, Durham et al. 2014, Oteros-Rozas et al. 2015, Hauck et al. 2016). Different approaches to stakeholder engagement emphasize the different benefits such engagement can confer, particularly in the context of social- ecological systems. For example, the multiple evidence-based approach argues that different knowledge systems (e.g., indigenous, local, and scientific) can make unique yet synergistic contributions to managing complex ecological systems (Tengö et al. 2014). The translational ecology approach contends that including decision makers and other stakeholders in the development of environmental research can help ensure that research is relevant and actionable for decision-making processes (Enquist et al. 2017). The degree of stakeholder integration in these processes can vary depending on the purpose of the collaboration, from low to fully integrated (Tress et al. 2005), with new frameworks involving stakeholders at varying strengths in the process of codesigning, coproducing, and codisseminating knowledge (Mauser et al. 2013).

Stakeholders are an especially important part of ecosystem services research, as what can be considered as an ecosystem service inherently involves the perceptions, needs, and values of the people who make use of and/or depend on the ecosystem (Haines-Young and Potschin 2010). The identification of ecosystem services therefore depends on careful assessment of which ecosystem structures and processes contribute to a population's needs and desires (Harrington et al. 2010, Hauck et

\footnotetext{
${ }^{1}$ Lund University Centre for Sustainability Studies, Lund, Sweden, ${ }^{2}$ Institute for Spatial and Landscape Development, ETH Zürich, Zürich, Switzerland, ${ }^{3}$ School of GeoSciences, University of Edinburgh, Edinburgh, UK, ${ }^{4}$ Department of Global Change Research, IMEDEA (CSIC-UIB), Institut Mediterrani d'Estudis Avançats, Esporles, Spain, ${ }^{5}$ Centre for Ecology, Evolution and Environmental Changes (cE3c), Faculdade de Ciências (FCUL), Universidade de Lisboa, Lisbon, Portugal, ${ }^{6}$ Institute for Environmental Studies, VU University Amsterdam, Amsterdam, The Netherlands, ${ }^{7}$ Institute of Earth and Environmental Science, University of Potsdam, Potsdam, Germany
} 
al. 2013, Spangenberg et al. 2015, Brunner and Grêt-Regamey 2016) - which implies engaging with this population to understand their needs and desires. As such, it would make sense for the identification of ecosystem services to go hand in hand with the identification of the stakeholders who rely on and appreciate these services.

However, many ecosystem services research projects lack stakeholder engagement. Reviewing local to regional ecosystem services case studies, Seppelt et al. (2011) showed that only 39\% of the included publications reported some form of stakeholder involvement. In a follow-up study, Lautenbach et al. (2015) found that the majority of reported studies still did not include stakeholder involvement. Spangenberg et al. (2015) found that some ecosystem service projects are driven by experts, who act as "superior referees" and, at a preliminary stage, identify which ecosystem services are relevant to be studied. Menzel and Teng (2010:908) warn that separating the identification and valuation of ecosystem services can result in projects that "do not effectively include people's actual values and needs and run the risk of being irrelevant for policy." This is, of course, based on a somewhat limited sample, as there are likely ecosystem services projects that are not designed as studies to be included in the published literature but rather aim to influence decision making through other channels.

There is also a gap between theory and practice in stakeholder involvement in ecosystem services-related research. In a metaanalysis of case-study literature about stakeholder engagement in natural resource management projects, Talley et al. (2016) cite both the difficulties of putting complex theoretical stakeholder engagement frameworks into practice and the fact that few of the case studies they examined systematically applied any framework. Reed et al. (2014:338) similarly found, based on interviews with researchers and stakeholders in 13 environmental management research projects, that knowledge exchange between researchers and stakeholders is "often conducted on an ad-hoc basis, based on 'what seems to work' with little theoretical, methodological, or empirical grounding..."

Practical frameworks do exist for engaging stakeholders in natural resource and environmental management research. For example, Talley et al. (2016) propose a "Five-Feature Framework" that includes: (1) set clear objectives, (2) systematically represent stakeholders, (3) use relevant methodologies, (4) create opportunities for coownership, and (5) reflect on processes and outcomes. Reed et al. (2014) propose "five principles for effective knowledge exchange" comprising design, represent, engage, impact, and reflect and sustain. Luyet et al. (2012) put forth a "framework to implement stakeholder participation in environmental projects" that includes stakeholder identification, characterization, and structuring; choice and implementation of participatory techniques; and evaluation of stakeholder participation. But even these frameworks lack simple guidance for putting the steps into practice. A number of tools and guidance documents aim to assist ecosystem services researchers with such aspects as stakeholder identification and analysis, selection of stakeholder engagement methods, and evaluation of stakeholder engagement processes (e.g., Walton et al. 2013, Durham et al. 2014, Slunge et al. 2017), but these often lack a concise framework to tie their extensive information together.
In this paper, we develop a framework comprising three key elements that ecosystem services researchers may want to consider to guide their overall approach to working with stakeholders. This framework is derived from interviews and discussions with the scientific experts leading 12 ecosystem services case studies and is based on their experiences with stakeholder engagement, both in terms of what they found effective and the challenges they faced. When the researchers began their work in 2011, they sought but were unable to find a simple and practicable framework to guide their stakeholder engagement processes. Frameworks that have been developed since then, such as those by Reed et al. (2014) and Talley et al. (2016), go a long way toward operationalizing stakeholder engagement but, based on our experiences, there is still room to simplify implementation.

Making stakeholder engagement easier for researchers does not, of course, imply that a stakeholder engagement process will automatically be successful. Among other things, it would be important to also consider the views of stakeholders to gauge the effectiveness of any stakeholder engagement process. However, given that, in our experience, even highly motivated and experienced researchers found stakeholder engagement challenging, making it easier and more practical to engage stakeholders is a good and necessary first step. We suggest that researchers who use our framework to guide their overall stakeholder engagement approach and to help anticipate issues and challenges will be in a better position for effective stakeholder engagement.

\section{METHODS}

\section{Case description}

We conducted this research within the European Commissionfunded project Operational Potential of Ecosystem Research Applications (OPERAs). OPERAs aimed to better operationalize the concept of ecosystem services into EU policy and practice and included 12 ecosystem services research case studies across different scales, geographies, and ecosystems that worked with stakeholders to better measure and manage ecosystem services (Table 1).

The purpose of stakeholder engagement was different for each of the OPERAs case studies. The Wine case study, for example, sought to influence the decision making of stakeholders in the wine value chain (growers, wineries, distributors, retailers) and thus engaged these stakeholders in order to understand the motivations and barriers they face in shifting to more sustainable practices. This understanding will help researchers recommend practices that not only increase ecosystem services but are more likely to be implemented by stakeholders. The Swiss Alps case study, on the other hand, sought to develop regional policy and management strategies that best balance the supply of and demand for mountain ecosystem services. It engaged both decision makers and local residents in envisioning their desired future landscapes, thus helping ensure that future development of the region is both sustainable and socially acceptable. Other motivations for engaging stakeholders included a desire to use specific tools to assess ecosystem service supply that require stakeholder data or input, achieve a specific management objective such as restoring a wetland, or increase the prominence that ecosystem services are given in decision making by local authorities. 
Table 1. Brief descriptions of the 12 case studies in the OPERAs European ecosystem services research project. More complete information is available on https://oppla.eul.

\begin{tabular}{ll}
\hline \hline Case Study & Project Title \\
\hline Balearic & $\begin{array}{l}\text { Blue Carbon in the Balearic Islands: } \\
\text { cobeneficiary management of seagrass } \\
\text { ecosystems. } \\
\text { Urban hybrid dunes in Barcelona }\end{array}$ \\
Barcelona & \\
Danube & $\begin{array}{l}\text { Traversing waters: recognizing wetland } \\
\text { ecosystems value in the Lower Danube }\end{array}$
\end{tabular}

\section{Objective}

To assess the cobeneficiary management of seagrass ecosystems for blue carbon in the Balearic Islands in order to develop strategies for mitigation of carbon dioxide emissions through conservation of coastal marine ecosystems.

To learn to construct and maintain dunes on urban beaches to optimize the flows of ecosystem services such as protection against sea level rise, and to learn how to shape social attitudes to make intensive recreational use of beaches compatible with protection of the dunes.

To identify and raise awareness of the societal, economic, and environmental values of wetlands, and to explore the relationship between restored and sustainably managed wetlands and socioeconomic welfare to inform decision making in the Danube river basin.

Dublin Cultural seascapes: sociocultural valuation of ecosystem services in Fingal, County Dublin, Ireland

European Pan European policy: trade-offs and synergies across Europe

To research the expression of cultural ecosystem services values in a coastal setting, and to consider the contribution of ecosystem services approaches to consultation within land-use planning.

To evaluate how recent and forthcoming EU policy developments affect the levels of ecosystem services and biodiversity in Europe, and how spatial policies and land management can navigate resulting trade-offs.

French Alps Land-use legacies: land use and ecosystem service scenarios in the Grenoble urban area

Global Global-scale prediction of ecosystem services to inform international policy

To analyze future land-use trajectories and their effects on networks of biodiversity and ecosystem services in the Grenoble urban area in order to inform territorial planning and management.

To use the ecosystem services concept to identify geographic areas and management solutions that synergistically support biodiversity conservation, climate change mitigation, and feeding an increasing global population, in order to inform policy decision processes at the international level.

Mediterranean Abandoned lands: agricultural shifts in the Mediterranean

To assess how changes in the way farmers manage their land in the

Mediterranean can lead to changes in sustainable provisioning of ecosystem services in order to inform future management strategies.

To employ the ecosystem services and natural capital concepts to promote improved management of the Montado multifunctional ecosystem, reconciling resource use with conservation interests.

More than cork: cultural landscapes in the

$\begin{array}{ll}\text { Montado } & \text { More than cork: cult } \\ \text { Montado (Portugal) }\end{array}$

Scottish Multiscale implementation of environmental policy in Scotland

To match the needs of land-use management and biodiversity policy in Scotland by contributing to the science, information, and assessment methods necessary to support policy implementation.

To explore which policy strategies can balance the supply of and demand for mountain ecosystem services in the future.

To understand how different players in the wine value chain (producers, retailers, consumers) influence wine production, and thus the ecosystem services provided by vineyard ecosystems, and to promote more sustainable vineyard management to increase ecosystem services.
Despite their different reasons for and approaches to stakeholder engagement, what links the case studies together is a common goal of working with stakeholders to guide decision making toward policies and practices that result in greater ecosystem services provision. The 12 case studies each engaged stakeholders to various degrees, and with varying amounts of challenge and success in terms of what the researchers hoped to get out of each engagement. They thus provide an excellent opportunity through which to explore the practical experiences of how stakeholder engagement in research can actually play out-and what researchers wish they would have known or better considered before starting the process.

\section{Study design}

To understand the key elements of stakeholder engagement in ecosystem services research, we asked the researchers leading each of the 12 case studies questions about different aspects of their stakeholder engagement processes. As we were most interested in how stakeholder engagement played out on the ground, we chose questions that focused more on how researchers went about engaging stakeholders than on why the stakeholders were engaged - the latter of which was already described in the design of each of the case studies. The questions addressed aspects including stakeholder identification, timing of stakeholder involvement, methods of stakeholder involvement, relationships between researchers and stakeholders, and stakeholders' interactions with each other. The questions also correspond with some of the key steps included in guidance documents such as the BiodivERsA Stakeholder Engagement Handbook (Durham et al. 2014).

Case-study leads were first asked to fill out a short email survey (Appendix 1), after which they were individually interviewed (Appendix 2) either in person during an OPERAs consortium meeting, or via video conferencing if they were unable to attend the meeting. As the case-study leads were internal OPERAs partners with a history of collaboration and deep involvement in 
the project, interview consent was obtained verbally after they had read the written description of the study. Both the survey and the interview questions addressed the same five factors. The survey was aimed at gathering background information and thus asked about the "how": e.g., "How did you identify stakeholders?" The interviews sought to gain insight into how successful the researchers felt the different aspects of the process were and thus focused on the "how well?": e.g., "Do you feel that your method of stakeholder engagement worked for you? Was there anything you would have done differently?" Interview responses were captured via field notes, with audio recordings also made in case clarifications were needed. Some researchers also followed up with additional information in writing.

Additional context for the paper was provided during two working sessions in which the case-study leads discussed the key questions that they thought an analysis of stakeholder engagement should address and reflected upon their experiences with stakeholder engagement so far. Materials in which the casestudy leads had previously discussed their work with stakeholder engagement, including project reports and websites, were also consulted.

Many of the researchers' interview responses pointed to factors contributing to their stakeholder engagement experiences that were broader than the specific topics the interview questions addressed. Thus, we took an inductive approach to analysis, performing a qualitative content analysis of the interview responses to determine key themes reported by the participants. This was done by the lead author, with help from the last author, first capturing individual responses (printed versions of field notes), then grouping by hand those responses that addressed similar topics until we reached a set of 12 unique topics. We identified these as the "components" of stakeholder engagement, representing unique aspects that one or more participants found essential to their experience. We then grouped these 12 individual components into higher-level themes, which we identified as the three "key elements" of stakeholder engagement.

\section{RESULTS}

Key elements and components of stakeholder engagement

We identified 12 components of stakeholder engagement, which we further grouped into three key elements - creating space, aligning motivations, and building trust — comprising three to five components each (Table 2).

Creating space

The first key element that emerged from our interviews with the case-study leads was the importance of creating space. The very existence of an ecosystem services research project creates a space - both to consider concepts and to physically meet - in which to bring together different people, viewpoints, and disciplines, and to foster relationships and communications that might otherwise be missing or contentious. We identified the components of creating space to include the roles of convening, conduits, and critical space.

Many case-study leads found their projects to be a means to convene stakeholders who would not otherwise interact with each other-such as local and national stakeholders in the Danube case study. The Dublin case-study lead similarly found that "the process brought together strange bedfellows, which facilitated the social learning and sharing of knowledge across the group."

Not all stakeholder gatherings are without contention, however, which led to discussion about the role of particular groups or organizations serving as conduits in order to help create a space in which different groups can effectively contribute. For example, the Danube case-study lead mentioned that their organization, as an NGO, is often a go-between for different groups:

"We've had some issues with different groups not listening to each other (for example, farmers vs. landowners, or residents thinking that scientists are from another world) but different groups can act as a neutral third party. For example, scientists can talk to an NGO, and residents will talk to an NGO, so the NGO becomes a conduit. Similarly, scientists can talk with both farmers and landowners even though the farmers and landowners may not talk to each other."

Case-study leads also discussed the importance of having a space for critical discussion, either about stakeholders' different goals and agendas or about the concept of ecosystem services itself. In the Dublin case study, "Stakeholders did have strong and different concerns, but saw the project workshops as a way to air their concerns and appreciated that someone cared what they had to say. The stakeholders saw conflict as OK." The Scottish case-study lead observed, "There has to be a place for critical assessment and criticism. Not everyone likes the ecosystem services concept. For some, it's about better resource management, not just about ecosystem services. Acknowledging this and providing a space for critical discussion opened the floor wider."

\section{Aligning motivations}

Another key element that emerged from our interviews was the importance of aligning motivations as much as possible between researchers and stakeholders. The case-study leads acknowledged that although it is likely impossible to completely align motivations, what is important is to lay them out at the beginning of a project so differences can be recognized and addressed. We identified the components of aligning motivations to include values, framing, goals, and benefits.

A number of case-study leads mentioned the importance-and challenges - of understanding what stakeholders care about, or value, and potentially adapting research approaches to those values. Inherent in this was the recognition that these values often differ between stakeholders, as well as between stakeholders and researchers. For example, as the Barcelona case-study lead found, "Community residents may care about sand dunes more for flood protection than biodiversity. The researchers' goal of building and protecting dunes to conserve biodiversity can still be accomplished, but we may need to change what benefits to emphasize so they resonate with residents."

Understanding values helped researchers frame, or present, the work in terms to which stakeholders can relate. For example, in many cases the term "ecosystem services" did not resonate with stakeholders even though they intuitively understood the concept. The Swiss Alps case-study lead found that "residents intuitively get ecosystem services, but not if you use that word. You have to connect it to their reality - e.g., you're benefiting from this thing, this is your ecosystem service." Relatedly, the Balearic case study used the term "ecosystem benefit," as stakeholders could not 
Table 2. Framework for effective stakeholder engagement in ecosystem services research, consisting of three key elements and their constituent 12 components. These elements were identified inductively via qualitative analysis of interview responses from researchers leading 12 European ecosystem services research case studies.

\begin{tabular}{|c|c|c|}
\hline Key Element & Component & Description \\
\hline \multirow[t]{3}{*}{ CREATING SPACE } & Convening & $\begin{array}{l}\text { Ecosystem services projects can serve as a means to bring together stakeholders who } \\
\text { may not otherwise interact and allow them to get to know each other }\end{array}$ \\
\hline & Conduit & $\begin{array}{l}\text { One actor, such as an NGO, can serve as a go-between for actors that wouldn't } \\
\text { otherwise interact }\end{array}$ \\
\hline & Critical Space & $\begin{array}{l}\text { Need for space for critical reflection (e.g., on problem definition, conflicts between } \\
\text { stakeholders, etc.) }\end{array}$ \\
\hline \multirow[t]{4}{*}{ ALIGNING MOTIVATIONS } & Values & $\begin{array}{l}\text { What some stakeholders value might differ from what researchers or other stakeholders } \\
\text { value }\end{array}$ \\
\hline & Framing & $\begin{array}{l}\text { Stakeholders may not understand the term "ecosystem services," but bring their own } \\
\text { intuitive understanding of the idea behind it }\end{array}$ \\
\hline & Goals & $\begin{array}{l}\text { Stakeholders and researchers may have different expectations for involvement or } \\
\text { influence in a project }\end{array}$ \\
\hline & Benefits & $\begin{array}{l}\text { Stakeholders often don't see what they'll get out of participating in a project or why } \\
\text { they should stay involved long term }\end{array}$ \\
\hline \multirow[t]{5}{*}{ BUILDING TRUST } & Existing Relationships & $\begin{array}{l}\text { Researchers often build on existing relationships and networks or select stakeholders } \\
\text { they already know }\end{array}$ \\
\hline & Time & Relationships take time to build \\
\hline & Approach & $\begin{array}{l}\text { Method of engagement depends in part on researchers' desired duration and level of } \\
\text { stakeholder engagement }\end{array}$ \\
\hline & Reputation & One individual can play an important role in project's start and/or success \\
\hline & Belonging & Researchers can be seen as either inside or outside the community \\
\hline
\end{tabular}

relate to the term "service" within an ecological framework. The Wine case study had success engaging a leading wine retailer when the researchers were able to speak the "language of business" and frame their discussions using terms reflected in the retailer's own sustainability-related publications.

Differences in values and the importance of framing also led to discussion of goals - particularly the importance of determining what the researchers' goals are in terms of what they hope to achieve in their project and when and how much these goals may be determined or influenced by the stakeholders. This is particularly important for helping set appropriate expectations. The Wine case study struggled with a chicken-and-egg situation in that "the research partners were eager to meet the needs of stakeholders, but stakeholders seemed to want a clear idea of what research could offer them before they decided to engage." The French Alps case study "made changes along the way based on stakeholder input to ensure we produced research for them." On the other hand, the Global case study, which built on models whose parameters and inputs were largely defined, had less of a role for stakeholders in influencing the research direction.

Many case-study leads referenced struggles to keep stakeholders engaged, noting that stakeholders are often asked to give a lot of their time and energy and thus need to understand what benefits they will get out of participating in a research project to maintain their engagement. For example, the Montado case-study lead found that "the most difficult thing is getting people to workshops. Either they don't know what they'll get out of it or they're burned out because they get called for lots of different workshops and often don't see any results or feedback after the workshops."

\section{Building trust}

The third key element that emerged from our interviews was that of building trust between researchers and stakeholders. Most of the interview responses related to trust focused on various aspects of relationships. We identified the components of building trust to include existing relationships, time, approach, reputation, and belonging.

Many of the case-study leads mentioned that they benefitted from having preexisting relationships with their stakeholders. In the Swiss Alps case study, "We could profit from a parallel project in which the coordinator and the principal investigator have been in touch with these people and been working in the study region for years. We believe that this continuity is one of the success factors of stakeholder engagement in our project." The European casestudy lead similarly found that "knowing the people was a great advantage for getting them to participate - without this, we would not have gotten this high-level group together."

Relatedly, many case-study leads referenced the time it takes to build trust and relationships. The French Alps case-study lead reflected, "The important thing is to build the network; once you have this, you can go to them with other projects and questions. We have spent a lot of time building relationships and, as a result, have had the same people involved since the beginning. It is very time consuming but worthwhile."

The approach to engaging with stakeholders was also identified as important, namely the importance of tailoring the approach to the desired level and duration of stakeholder engagement. A number of case-study leads talked about the importance of meeting people face to face, particularly if they were seeking deeper or longer-term engagement. The Scottish case-study leads built an entire community of practice for ecosystem services work beyond just their OPERAs project early on, the result of which is "we now have a pool of stakeholders who trust us and will come to us." On the other hand, when the Montado case study wanted to engage residents with whom they did not already have 
relationships in a one-time, electronic survey, they reached out indirectly through a company that convenes panels representing different regions, which was sufficient for their needs.

Many case-study leads discussed the important role of a key person or organization whose reputation can help make or break a project. The Mediterranean case-study lead "had a strong relationship with one key contact (an agronomist), who has helped us be able to build out a group with strong relationships." The lead for the Barcelona case study had a strong track record of success, having won an international prize for a previous project, which helped the current project go forward, in part because "it was seen as low risk; you can bet on a person who has done a good project." The Balearic case-study lead was "surprised at how willing people with whom we didn't have a previous relationship were to engage" and reflected that it could have been in part because the researchers are part of a well-respected research institution in a small community.

Furthermore, several case-study leads talked about the importance of being perceived as belonging to the local community. In the Swiss Alps case study, "We did in-person surveys using students born in the same area with the same dialect, which worked very well. Also, our first workshop had a researcher with close connections to the area and the people, which attracted a lot of attendees." The Wine case study lacked this, with the casestudy lead reflecting, "I felt I was viewed a bit suspiciously as an outsider. It was hard to explain that I was from California, now based in Sweden, and wanting to study English wine." However, both the Scottish and Montado case-study leads saw ways to overcome this, with the latter noting, "Since the goal of our project is to help influence management decisions at the farm level, approaching stakeholders with the support of the landowner or land manager may be worthwhile."

\section{DISCUSSION}

\section{Comparison of the key elements and components to previous findings}

Having identified from the case-study researchers' experiences the key elements of creating space, aligning motivations, and building trust, we then looked to see if and how others have addressed these ideas in the literature. We found that other researchers have also emphasized one or more of the three elements and many of the 12 components of stakeholder engagement that resulted from our research, although not necessarily using the same terminology and not in the same groupings, nor-most importantly for our researchers' stated needs-linked together in a simple and practicable framework. Although our findings broadly align with previous work, the specific groupings we propose are likely one of several possible ways to structure and present our data, and we recognize the inherent subjectivity in such a classification of related and interwoven elements. We have focused here on presenting a simple, logical, and easily implementable framework; other arrangements of the components could be possible.

In terms of creating space, the researchers and stakeholders interviewed by Reed et al. (2014: 341) discussed the need for a "safe space" where knowledge, skills, and ideas could be shared, explored, adapted, and applied. This concept is also echoed by Clark et al. (2016b: 4615) in their discussion of "boundary work," namely the importance of having a safe space in which to bridge differences in perspectives and approaches. The ATEAM (Advanced Terrestrial Ecosystem Assessment and Modelling) project pointed toward the idea of critical space, citing "an atmosphere...in which questioning comments and constructive criticism were encouraged and valued" (de la Vega-Leinert et al. 2008: 116). Cash et al. (2003: 8090) discuss the importance of efforts to link science and sustainable development serving as "venues for negotiation and mediation," whereas Reed (2008) notes that better decisions can sometimes result from taking a more deliberative approach rather than trying to reach consensus among different actors. The importance of conduits is addressed by many, often in terms of knowledge brokers or professional facilitators (e.g., Reed 2008, Durham et al. 2014, Reed et al. 2014, Gramberger et al. 2015). (We chose to use the term "conduit," which was used by one of the interviewees to describe their role, to also capture situations in which two groups share information through a neutral third party without necessarily being in direct contact with each other.)

Aligning motivations between researchers and stakeholders is also addressed by a number of researchers. Durham et al. (2014), in either direct or indirect terms, touch on each of the components we identified, including approaching projects in ways that are relevant to stakeholders (values, framing), managing expectations and establishing clear aims and objectives (goals), and identifying the benefits for stakeholders (benefits). Reed et al. (2014: 340) include in their themes for effective knowledge exchange "understand what everyone wants" (goals), "keep your goals in mind"(goals), "understand different motivations"(values), "keep it simple" (framing) and "deliver quick wins" (benefits). The ATEAM project illustrated some of the potential differences between researcher and stakeholder motivations, noting "sometimes conflicting priorities" (de la Vega-Leinert et al. 2008: 120).

Building trust, in particular, was mentioned as a key aspect of stakeholder engagement by many different researchers. Boschetti et al. (2016), for example, address the importance of trust for balancing differences in knowledge and power relations often present in sustainability challenges. Ruckelshaus et al. (2015) cite the importance of building trust with decision makers as one of the biggest lessons they have learned in working with projects aimed at integrating ecosystem services into decision making around the world. Reed (2008), based on a systematic literature review of stakeholder participation in environmental management, posits that "stakeholder participation needs to be underpinned by a philosophy that emphasizes empowerment, equity, trust and learning." Trust also both contributes to and results from stakeholders' perceptions of whether researchers and their work are credible, salient, and legitimate (Clark et al. 2016a). Although some researchers linked trust to different aspects of building relationships like we did (e.g., Reed 2008, Walton et al. 2013, Reed et al. 2014), nearly every component we found across all three key elements was also mentioned by different researchers as contributing to building trust. For example, trust can come from aspects we related to aligning motivations, such as clear problem definitions (Enquist et al. 2017) and clarity of intended outcomes (Reed et al. 2014), as well as those we included in creating space, such as opportunities for mutual learning and understanding (Reed 2008, Enquist et al. 2017). 


\section{Comparison of our framework to existing frameworks}

Recent frameworks put forth by Luyet et al. (2012), Reed et al. (2014), and Talley et al. (2016) all seek, as we do, to make stakeholder engagement more practicable. However, based on our experiences, there are two aspects that these frameworks lack and that our framework thus seeks to address: simple guidance for putting their different steps into practice and information that can help researchers consider potential issues and challenges before they arise. Luyet et al. (2012) provide a literature-based overview of possible tools for each step of their framework and note that the choice of each depends on context, but do not include clear information to help researchers choose between them. Talley et al. (2016) do include two guiding questions for each step to help with operationalization, but do not touch on potential issues that might arise at each point. Reed et al. (2014), however, do put forth such considerations and include some broad guidance, but the latter could be simplified even further. As discussed below and illustrated in Tables 3-5, our framework includes both guiding questions and considerations that, combined, can help make stakeholder engagement easier for researchers.

Another difference is in the sequence of the frameworks. Talley et al. (2016) proceed directly from setting goals for the engagement to identifying stakeholders; the issue of how open the research direction is to stakeholder feedback, for example, does not come until step four (create opportunities for coownership), after selecting relevant methodologies. Luyet et al. (2012) start immediately with stakeholder identification as the first step. Reed et al. (2014) note that there is overlap between their five principles and thus present them in a round rather than step-wise manner, but integrate them throughout the stakeholder engagement process. Whereas these frameworks tend to focus on the entire stakeholder engagement process, ours is meant to be used primarily in the research design and precede the actual engagement. And although there are overlaps between our framework and theirs-all ask researchers to consider their desired degree of stakeholder involvement, for example-we propose that our framework largely fits within, but also greatly expands upon, the beginning of each of these frameworks. It also does much to inform the other steps. By thinking through the components related to creating space, aligning motivations, and building trust at the very beginning of a project, researchers will likely be in a better position to effectively identify stakeholders, select engagement methods, and proceed with the rest of their stakeholder engagement process.

Despite the existing frameworks in the literature, evidence suggests that researchers often still struggle to include stakeholders in ecosystem services research. A number of the challenges that the OPERAs case-study researchers experienced, and that led to the creation of this framework, are also echoed by researchers in other large research projects. For example, in reflecting on their work with stakeholders across 27 ecosystem services case studies, researchers in the EU project OpenNESS (Operationalisation of Natural Capital and Ecosystem Services) identified differences in interests and expectations between researchers and stakeholders, benefits and risks of working with stakeholders with whom researchers already have existing relationships, and challenges of avoiding stakeholder burnout as issues that warrant further attention and discussion (Hauck et al. 2016). Researchers in the ATEAM project noted a "mismatch between scientists' and stakeholders' interests and expectations" (de la Vega-Leinert et al. 2008: 119). Oteros-Rozas et al. (2015), in their analysis of 23 participatory scenario-planning case studies, identified lack of stakeholder diversity and continuity of participation as barriers to successful stakeholder engagement. Such experiences further illustrate the need for a stakeholder engagement framework that can be easily implemented and can help researchers anticipate and consider key questions and issues before challenges arise.

\section{Putting the framework into practice}

Based on researchers' experiences from the case studies, we now discuss 12 suggested questions that researchers can ask themselves to help put each of the three key elements and their associated components into practice (Tables 3-5). We identified these questions after looking back on the case studies, thus essentially reflecting what researchers wished they would have asked themselves at the beginning of their stakeholder engagement processes. The questions can help inform the design of stakeholder engagement, given the specific research project goals. We also highlight some considerations, both pro and con, that can help determine the answers to these questions. These are also based on the researchers' experiences and are particularly informed by instances in which specific components played out both positively and negatively across different case studies. Such a simple approach to implementation is what we found to be missing from other stakeholder engagement frameworks.

Although we intend the framework to be used primarily during the research design phase, not all aspects of a stakeholder engagement process can be anticipated. In addition, as many researchers have noted (e.g., Reed 2008, Ruckelshaus et al. 2015, Talley et al. 2016, Enquist et al. 2017), stakeholder engagement works best as an iterative process. Therefore, we recommend revisiting the framework throughout the project as needed.

\section{Creating space}

Given that different stakeholders have different interests, it is important for researchers to consider if and how they want to bring these different interests together, how much space they want to allow for critical discussion, and whether there is a role for particular stakeholders to serve as conduits between others (Table 3 ). As one example of creating space in practice, some of the casestudy researchers strategically engaged different groups of stakeholders at different times to keep discussions and project progress from getting sidetracked, whereas others found that their project provided a venue in which traditionally opposing stakeholders could have their differences acknowledged and build understanding.

\section{Aligning motivations}

The diversity of stakeholders involved in ecosystem services projects also brings with it a diversity of values, knowledge, goals, and desired benefits. It is important that ecosystem services researchers consider how to manage these differences to reach a common objective, but in order to do so, researchers first need to be clear about their own values, knowledge, expectations, and desired benefits, as well as how much they might be willing to adapt their project to better align with stakeholder needs and desires. Table 4 includes some questions and considerations that can help researchers understand their own motivations and think about if and how they might align with those of stakeholders. As 
Table 3. Questions and considerations to guide researchers in creating space, derived from the experiences of researchers leading 12 ecosystem services research case studies.

\begin{tabular}{|c|c|c|}
\hline Components & $\begin{array}{l}\text { Questions for researchers to ask themselves to help create } \\
\text { space }\end{array}$ & Considerations \\
\hline Convening & $\begin{array}{l}\text { To what degree do we want to bring together stakeholders } \\
\text { who don't usually interact? }\end{array}$ & $\begin{array}{l}+\quad \text { Good opportunity to build trust between stakeholders } \\
\text { - } \quad \text { Can lead to conflicts }\end{array}$ \\
\hline Conduit & $\begin{array}{l}\text { Is there a role for individuals or organizations to serve as } \\
\text { conduits between certain stakeholders? }\end{array}$ & $\begin{array}{l}\text { + Can be beneficial to increase lines of communication and } \\
\text { build understanding } \\
\text { - } \quad \text { Adds an additional layer between groups }\end{array}$ \\
\hline Critical Space & $\begin{array}{l}\text { How much space do we want to allow for critical } \\
\text { discussion? }\end{array}$ & $\begin{array}{l}\text { + Lets stakeholders' concerns be heard and can give them } \\
\text { confidence they're being listened to } \\
\text { - Can sidetrack project }\end{array}$ \\
\hline
\end{tabular}

Table 4. Questions and considerations to guide researchers in aligning motivations, derived from the experiences of researchers leading 12 ecosystem services research case studies.

\begin{tabular}{|c|c|c|}
\hline Components & $\begin{array}{l}\text { Questions for researchers to ask themselves to help align } \\
\text { motivations }\end{array}$ & Considerations \\
\hline Values & $\begin{array}{l}\text { What do we care about, and how much do we want that to } \\
\text { be influenced by stakeholders? }\end{array}$ & $\begin{array}{l}+\quad \text { Understanding what stakeholders care about can help align } \\
\text { motivations } \\
\text { - Can be difficult if values differ from researchers' and/or } \\
\text { between stakeholders }\end{array}$ \\
\hline Framing & $\begin{array}{l}\text { Are we presenting our project in a way that resonates with } \\
\text { stakeholders' knowledge and values? }\end{array}$ & $\begin{array}{l}+\quad \text { Approaching projects in ways stakeholders can relate to can } \\
\text { lead to greater understanding } \\
\text { - May not mesh with the researchers' priorities }\end{array}$ \\
\hline Goals & What outcomes do we want to achieve with this project? & $\begin{array}{l}+\quad \text { Stating clear goals can help set expectations } \\
\text { - May lead to chicken-and-egg situation where researchers } \\
\text { want to shape project to meet stakeholders' needs but } \\
\text { stakeholders first want to know what researchers can offer }\end{array}$ \\
\hline Benefits & $\begin{array}{l}\text { Have we made clear what benefits stakeholders will get out } \\
\text { of participating in our project? }\end{array}$ & $\begin{array}{l}+\quad \text { Ensuring stakeholders see some benefit to participating can } \\
\text { help attract and retain them } \\
\text { - Desired benefits may differ among stakeholders }\end{array}$ \\
\hline
\end{tabular}

Table 5. Questions and considerations to guide researchers in building trust, derived from the experiences of researchers leading 12 ecosystem services research case studies.

\begin{tabular}{|c|c|c|}
\hline Components & $\begin{array}{l}\text { Questions for researchers to ask themselves to help build } \\
\text { trust }\end{array}$ & Considerations \\
\hline Existing Relationships & $\begin{array}{l}\text { To what extent should we work with stakeholders we } \\
\text { already know? }\end{array}$ & $\begin{array}{l}+\quad \text { May already have trust and buy-in } \\
\text { - } \quad \text { Could raise questions about representativeness or lead to } \\
\text { stakeholder burnout }\end{array}$ \\
\hline Time & $\begin{array}{l}\text { Is there time to establish relationships with new } \\
\text { stakeholders? }\end{array}$ & $\begin{array}{l}+\quad \text { Can be worthwhile to take the time to build relationships } \\
\text { and networks } \\
\text { - May be limited by time constraints }\end{array}$ \\
\hline Approach & $\begin{array}{l}\text { Do we want to engage stakeholders face to face or would } \\
\text { other methods accomplish our goals? }\end{array}$ & $\begin{array}{l}+\quad \text { Face-to-face methods can be good for deeper engagements } \\
\text { - Face-to-face methods can be difficult given scale and time } \\
\text { constraints }\end{array}$ \\
\hline Reputation & $\begin{array}{l}\text { Is there a key person who should be included in the } \\
\text { project? }\end{array}$ & $\begin{array}{l}+\quad \text { Can be good for making connections and attracting } \\
\text { stakeholders } \\
\text { - Can backfire if not the right person }\end{array}$ \\
\hline Belonging & How do we as researchers fit into the community? & $\begin{array}{l}+\quad \text { Researchers could potentially be seen as an objective third } \\
\text { party } \\
\text { - } \quad \text { Being seen as outside the community can make it difficult } \\
\text { to be accepted by stakeholders }\end{array}$ \\
\hline
\end{tabular}

one example, depending on the goals of their project, some of the case-study researchers found it most useful to engage stakeholders right at the beginning in helping define the problem and/or approach, whereas others brought (or wished they had brought) stakeholders in later, after the project had more structure.

\section{Building trust}

Different stakeholders may benefit in different ways from a particular ecosystem and may also experience different costs and benefits from any proposed environmental management changes resulting from an ecosystem services project. Thus, in order to 
meaningfully engage with these stakeholders, it is important that researchers earn their trust. Table 5 includes some questions and considerations that can help researchers determine how to go about building this trust. For example, nearly all of the case-study leads noted advantages of working with stakeholders with whom they had existing relationships, but this also raised questions about the representativeness of the stakeholders. Similarly, although a key person could recruit, engage, and mobilize other stakeholders, one case-study lead found this approach to be a hindrance when it emerged that the key stakeholder initially identified was actually quite a polarizing figure within the local community.

\section{Different paths between the key elements}

The relationships between the key elements of creating space, aligning motivations, and building trust are complex and context dependent, and many of the elements build on each other. For example, bringing together stakeholders with different viewpoints (creating space) may in turn build trust with the researchers and increase the stakeholders' motivation for wanting to participate in a project. On the other hand, stakeholders may not be willing to come together (creating space) if they do not already have a relationship with the researchers (building trust).

Indeed, depending on the context of their project, researchers followed different paths to create space, align motivations, and build trust. For example, in the Wine case study, which was a new project, the space existed (in the form of the research project), but the researchers lacked relationships with stakeholders. In trying to build these relationships, the researchers realized that their own goals were not entirely clear, and thus it was difficult to align motivations with potential stakeholders. The researchers went back and clarified their goals, and then worked to build trust with a new group of stakeholders. For the Barcelona case study, the researchers' motivation (building sand dunes) was clear. The researchers then worked to build trust with separate groups of stakeholders, namely the administration and local residents. With that trust established, the researchers then sought to bring those groups together (creating space).

Although it is impossible to anticipate exactly how a stakeholder engagement process might go, what is important is to think through the questions and considerations ahead of time and to develop a strategy to address any potentially negative situations should they arise.

\section{CONCLUSION}

Involving stakeholders in research demands thoughtful reflection from the researchers about what kind of space they want to create and what will best meet the needs of the stakeholders. In addition, understanding their own motivations, as well as what motivates stakeholders, will help researchers decide when and how to involve stakeholders, identify areas of common ground and potential disagreement, frame the project appropriately, set expectations, and ensure each is able to see benefits of engaging with each other. Finally, as with any relationship, building relationships with stakeholders can be difficult, but considering the roles of existing relationships, time, approach, reputation, and belonging can help build mutual trust.

Both academics and stakeholders can benefit from insights that encourage more successful interactions between them. Although further research could explore the perspective and experience of stakeholders, here we have focused on the researcher's view. Given the potential contributions of stakeholder engagement toward both better understanding problems and creating meaningful solutions (e.g., Reed 2008, Lang et al. 2012, Luyet et al. 2012, Durham et al. 2014, Tengö et al. 2014, Enquist et al. 2017), we put forth this framework to help promote collaborations between researchers and stakeholders by making it easier for researchers to set up such engagement. We suggest that a research design that considers how to create the space in which researchers and stakeholders will meet, align motivations between researchers and stakeholders, and build mutual trust, will help foster productive researcher-stakeholder relationships. Our hope is that the experiences we have gathered and synthesized here can be used in practice by academics looking to meaningfully engage stakeholders in ecosystem services research.

\section{Responses to this article can be read online at: http://www.ecologyandsociety.org/issues/responses. php/10061}

\section{Acknowledgments:}

We would like to thank all of the OPERAs project case study researchers who participated in the interviews and discussed their experiences with stakeholder engagement in ecosystem services research. Special thanks to those who provided feedback on drafts of this paper, including Craig Bullock, Wolfgang Cramer, Ilse Geijzendorffer, Sandra Lavorel, and Astrid van Teeffelen. Thank you also to Lund University Centre for Sustainability Studies (LUCSUS) and Lund University Library's Article Processing Charges Fund for open access publication fee support. This work was supported by the EU's Seventh Framework Programme for Research (FP7) as part of the project OPERAs, Grant Agreement No 308393 .

\section{LITERATURE CITED}

Boschetti, F., C. Cvitanovic, A. Fleming, and E. Fulton. 2016. A call for empirically based guidelines for building trust among stakeholders in environmental sustainability projects. Sustainability Science 11:855-859. http://dx.doi.org/10.1007/s11625-016-0382-4

Brunner, S. H., and A. Grêt-Regamey. 2016. Policy strategies to foster the resilience of mountain social-ecological systems under uncertain global change. Environmental Science and Policy 66:129-139. http://dx.doi.org/10.1016/j.envsci.2016.09.003

Cash, D. W., W. C. Clark, F. Alcock, N. M. Dickson, N. Eckley, D. H. Guston, J. Jäger, and R. B. Mitchell. 2003. Knowledge systems for sustainable development. Proceedings of the National Academy of Sciences 100(14):8086-8091. http://dx.doi. org/10.1073/pnas.1231332100

Clark, W. C., L. van Kerkhoff, L. Lebel, and G. C. Gallopin. 2016a. Crafting usable knowledge for sustainable development. Proceedings of the National Academy of Sciences 113(17):4570 4578. http://dx.doi.org/https://doi.org/10.1073/pnas.1601266113

Clark, W. C., T. P. Tomich, M. van Noordwijk, D. Guston, D. Catacutan, N. M. Dickson, and E. McNie. 2016b. Boundary work for sustainable development: natural resource management at the 
Consultative Group on International Agricultural Research (CGIAR). Proceedings of the National Academy of Sciences 113 (17):4615-4622. http://dx.doi.org/https://doi.org/10.1073/ pnas.0900231108

de la Vega-Leinert, A. C., D. Schröter, R. Leemans, U. Fritsch, and J. Pluimers. 2008. A stakeholder dialogue on European vulnerability. Regional Environmental Change 8:109-124. http:// dx.doi.org/10.1007/s10113-008-0047-7

Durham E., H. Baker, M. Smith, E. Moore, and V. Morgan. 2014. The BiodivERsA stakeholder engagement handbook. BiodivERsA, Paris, France.

Enquist, C. A. F., S. T. Jackson, G. M. Garfin, F. W. Davis, L. R. Gerber, J. A. Littell, J. L. Tank, A. J. Terando, T. U. Wall, B. Halpern, J. K. Hiers, T. L. Morelli, E. McNie, N. L. Stephenson, M. A. Williamson, C. A. Woodhouse, L. Yung, M. W. Brunson, K. R. Hall, L. M. Hallett, D. M. Lawson, M. A. Moritz, K. Nydick, A. Pairis, A. J. Ray, C. Regan, H. D. Safford, M. W. Schwartz, and M. R. Shaw. 2017. Foundations of translational ecology. Frontiers in Ecology and the Environment 15(10):541-550. http://dx.doi.org/10.1002/fee.1733

Future Earth. 2014. Strategic research agenda 2014: priorities for a global sustainability research strategy. [online] URL: http:// www.futureearth.org/sites/default/files/strategic_research_agenda_2014. pdf

Gramberger, M., K. Zellmer, K. Kok, and M. J. Metzger. 2015. Stakeholder integrated research (STIR): a new approach tested in climate change adaptation research. Climactic Change 128 (3):201-214. http://dx.doi.org/10.1007/s10584-014-1225-x

Haines-Young, R., and M. Potschin. 2010. The links between biodiversity, ecosystem services and human well-being. Pages 110-139 in D. Raffaelli and C. Frid, editors. Ecosystem ecology: a new synthesis. Cambridge University Press, Cambridge, UK. http://dx.doi.org/10.1017/CBO9780511750458.007

Harrington, R., C. Anton, T. P. Dawson, F. de Bello, C. K. Feld, J. R. Haslett, and P. A. Harrison. 2010. Ecosystem services and biodiversity conservation: concepts and a glossary. Biodiversity and Conservation 19:2773-2790. http://dx.doi.org/10.1007/ s10531-010-9834-9

Hauck, J., C. Görg, R. Varjopuro, O. Ratamäki, and K. Jax. 2013. Benefits and limitations of the ecosystem services concept in environmental policy and decision making: some stakeholder perspectives. Environmental Science and Policy 25:13-21. http:// dx.doi.org/10.1016/j.envsci.2012.08.001

Hauck, J., H. Saarikoski, F. Turkelboom, and H. Keune. 2016. Stakeholder involvement in ecosystem service decision-making and research. In M. Potschin and K. Jax, editors. OpenNESS ecosystem services reference book. EC FP7 Grant Agreement no. 308428. [online] URL: http://www.openness-project.eu/library/ reference-book

Kueffer, C., and G. Hirsch Hadorn. 2008. How to achieve effectiveness in problem-oriented landscape research: the example of research on biotic invasions. Living Reviews in Landscape Research 2:2. http://dx.doi.org/10.12942/lrlr-2008-2

Lang, D. J., A. Wiek, M. Bergmann, M. Stauffacher, P. Martens, P. Moll, M. Swilling, and C. J. Thomas. 2012. Transdisciplinary research in sustainability science: practice, principles, and challenges. Sustainability Science 7 (Supplement 1):25-43. http:// dx.doi.org/10.1007/s11625-011-0149-x

Lautenbach, S., A.-C. Mupepele, C. F. Dormann, H. Lee, S. Schmidt, S. S. K. Scholte, R. Seppelt, A. J. A. van Teeffelen, W. Verhagen, and M. Volk. 2015. Blind spots in ecosystem services research and implementation. bioRxiv: 033498. http://dx.doi. org/10.1007/s10113-018-1457-9

Luyet, V., R. Schlaepfer, M. B. Parlange, and A. Buttler. 2012. A framework to implement stakeholder participation in environmental projects. Journal of Environmental Management 11:213-219. http://dx.doi.org/10.1016/j.jenvman.2012.06.026

Mauser, W., G. Klepper, M. Rice, B. S. Schmalzbauer, H. Hackmann, R. Leemans, and H. Moore. 2013. Transdisciplinary global change research: the co-creation of knowledge for sustainability. Current Opinion in Environmental Sustainability 5:420-431. http://dx.doi.org/10.1016/j.cosust.2013.07.001

Menzel, S., and J. Teng. 2010. Ecosystem services as a stakeholderdriven concept for conservation science. Conservation Biology 24:907-909. http://dx.doi.org/10.1111/j.1523-1739.2009.01347.x

Oteros-Rozas, E., B. Martín-López, T. Daw, E. L. Bohensky, J. Butler, R. Hill, J. Martin-Ortega, A. Quinlan, F. Ravera, I. RuizMallén, M. Thyresson, J. Mistry, I. Palomo, G. D. Peterson, T. Plieninger, K. A. Waylen, D. Beach, I. C. Bohnet, M. Hamann, J. Hanspach, K. Hubacek, S. Lavorel, and S. Vilardy. 2015. Participatory scenario planning in place-based social-ecological research: insights and experiences from 23 case studies. Ecology and Society 20(4): 32. http://dx.doi.org/https://doi.org/10.5751/ ES-07985-200432

Reed, M. S. 2008. Stakeholder participation for environmental management: a literature review. Biological Conservation 141:2417-2431. http://dx.doi.org/10.1016/j.biocon.2008.07.014

Reed, M. S., L. C. Stringer, I. Fazey, A. C. Evely, and J. H. J. Kruijsen. 2014. Five principles for the practice of knowledge exchange in environmental management. Journal of Environmental Management 146:337-345. http://dx.doi.org/10.1016/j. jenvman.2014.07.021

Ruckelshaus, M., E. McKenzie, A. Guerry, G. Daily, P. Kareiva, S. Polasky, T. Ricketts, N. Ghababati, S. A. Wood, and J. Bernhardt. 2015. Notes from the field: lessons learned from using ecosystem service approaches to inform real-world decisions. Ecological Economics 115:11-21. http://dx.doi.org/10.1016/j. ecolecon.2013.07.009

Seppelt, R., C. F. Dormann, F. V. Eppink, S. Lautenbach, and S. Schmidt. 2011. A quantitative review of ecosystem service studies: approaches, shortcomings and the road ahead. Journal of Applied Ecology 48(3):630-636. http://dx.doi.org/10.1111/j.1365-2664.2010.01952. $\underline{\mathrm{X}}$

Slunge, D., O. Drakenberg, A. Ekbom, M. Göthberg, Å. Knaggård, and U. Sahlin. 2017. Stakeholder interaction in research processes - a guide for researchers and research groups. University of Gothenburg, Gothenburg, Sweden.

Spangenberg, J. H., C. Görg, and J. Settele. 2015. Stakeholder involvement in ESS research and governance: between conceptual ambition and practical experiences_-risks, challenges and tested 
tools. Ecosystem Services 16:201-211. http://dx.doi.org/10.1016/ j.ecoser.2015.10.006

Talley, J. L., J. Schneider, and E. Lindquist. 2016. A simplified approach to stakeholder engagement in natural resource management: the five-feature framework. Ecology and Society 21 (4): 38. http://dx.doi.org/10.5751/ES-08830-210438

Tengö, M., E. S. Brondizio, T. Elmqvist, P. Malmer, and M. Spierenburg. 2014. Connecting diverse knowledge systems for enhanced ecosystem governance: the multiple evidence base approach. Ambio 43(5):579-591. http://dx.doi.org/10.1007/ s13280-014-0501-3

Tress, B., G. Tress, and G. Fry. 2005. Clarifying integrative research concepts in landscape ecology. Landscape Ecology 20:479-493. http://dx.doi.org/10.1007/s10980-004-3290-4

Walton, A., M. Gomei, and G. Di Carlo. 2013. Participatory approaches for the planning and development of marine protected areas. World Wide Fund for Nature, Rome Italy and NOAA - National Marine Sanctuary Program, Washington, D. C., USA. [online] URL: http://awsassets.panda.org/downloads/ stakeholder engagement.pdf

Zscheischler, J., and S. Rogga. 2015. Transdisciplinarity in land use science - a review of concepts, empirical findings and current practices. Futures 65:28-44. http://dx.doi.org/10.1016/j.futures.2014.11.005 
Appendix 1. Written survey questions

Each of the 12 OPERAs case study leads were asked to answer these specific survey questions via email.

Stakeholder identification

How were stakeholders identified?

How was it decided who not to include as stakeholders?

Timing of stakeholder involvement

At what points in your OPERAs project were stakeholders involved?

Methods of stakeholder involvement

What methods did you use to involve stakeholders?

Nature of stakeholder relationships

What was the nature of the relationships with these stakeholders before OPERAs?

Inter-stakeholder interactions

How did stakeholders interact with each other? 
Appendix 2. In-person interview questions

These questions served to guide the in-person semi-structured interviews with each of the 12 OPERAs case study leads.

\section{Stakeholder identification}

Were your stakeholder identification method(s) successful?

Is there anything you would you have done differently?

Was anyone not at the table who should have been?

Was anyone included who should not have been?

Timing of stakeholder involvement

Were the points at which you brought in stakeholders appropriate? For example, did it make sense to include stakeholders from the beginning to help shape your project?

Were new stakeholders identified as the project progressed?

Should anyone have been brought in earlier or later?

\section{Methods of stakeholder involvement}

Did you feel that your method(s) of stakeholder engagement (e.g. workshops, surveys) worked for you?

Did your methods vary by stakeholder?

Nature of stakeholder relationships

How did the status of your relationships with your stakeholders (e.g. whether you already knew them) affect engagement?

For new partners, was there sufficient time and venues through which to build trust and understanding to successfully execute the project?

\section{Inter-stakeholder interactions}

How did your stakeholders interact with each other? For example, were there any conflicts? Were these stakeholders who had worked together before or did OPERAs bring them together?

Did the mix of stakeholders and/or existing relationships/conflicts between stakeholders affect the project (positively or negatively)? 